\title{
Theory-based practice as plural interpretations: A case of the the integration of the Humanbecoming theory in a palliative care setting
}

\author{
Diane Tapp \\ Laval University, Faculty of Nursing, diane.tapp@fsi.ulaval.ca \\ Mireille Lavoie \\ Laval University, mireille.lavoie@fsi.ulaval.ca \\ Nicolas Vonarx \\ Laval University, nicolas.vonarx@fsi.ulaval.ca
}

Follow this and additional works at: https://qane-afi.casn.ca/journal

Part of the Adult and Continuing Education and Teaching Commons, and the Other Nursing Commons

\section{Recommended Citation}

Tapp, Diane; Lavoie, Mireille; and Vonarx, Nicolas (2016) "Theory-based practice as plural interpretations: A case of the the integration of the Humanbecoming theory in a palliative care setting," Quality Advancement in Nursing Education - Avancées en formation infirmière: Vol. 2: Iss. 2, Article 4.

DOI: https://doi.org/10.17483/2368-6669.1078

This Article is brought to you for free and open access by Quality Advancement in Nursing Education - Avancées en formation infirmière. It has been accepted for inclusion in Quality Advancement in Nursing Education - Avancées en formation infirmière by an authorized editor of Quality Advancement in Nursing Education - Avancées en formation infirmière. 


\section{Theory-based practice as plural interpretations: A case of the the integration of the Humanbecoming theory in a palliative care setting}

\section{Cover Page Footnote}

Funding acknowledgments The first author is grateful for the financial support received from Quebec's Government and the Faculty of Nursing of Laval University (scholarship) during this study.

Reconnaissance du financement: l'auteure principale est reconnaissante pour l'appui financier reçu du Gouvernement du Québec et de la Faculté des sciences infirmières de l'Université Laval (bourse) pendant la durée de cette recherche. 


\section{Background}

Theory-based practice is abundantly documented in the nursing discipline. Nursing theorists and their supporters argue that these theories and models are the foundation of nursing knowledge since they clarify the particular nature of nursing and determine ways of developing this knowledge (Fawcett, 2005). Some authors have asserted that theory-based practice improves nurses' attitudes and behaviours toward patients by rapidly transforming their representation of what nursing and health are and, therefore, the nurses' goals (Cody, 2013; Fawcett \& DesantoMadeya, 2013; George, 2011; Meleis, 2007; Parker, 2006; Parker \& Smith, 2010). Indeed, nurses who learned and consciously enacted theory within their practice reported having a more accurate representation of their professional mandate, better relationships with patients and colleagues, and greater job satisfaction (Bournes \& Ferguson-Paré, 2007; Flanagan, 2009; Legault \& Ferguson-Paré, 1999; MacLeod Dyess, Boykin, \& Bulfin, 2013; Mitchell, 1999; Northrup \& Cody, 1998; Santopinto \& Smith, 1999). Referring to the implementation of Watson's theory, St-Germain, Blais, and Cara (2008) showed that these effects were mainly attributed to positive feedback emanating from patients and their families. Similarly, Mitchell (1999) reported that patients and families attested that nurses were more attentive, took more time to discuss things that were important to them, and, most importantly, gave them the impression of being a whole person rather than a number or a "disease" (Mitchell, 1999). At a more concrete level, Northrup and Cody (1998) found a decline in the use of physical and chemical restraints after implementing the Humanbecoming theory. Legault and Ferguson-Paré (1999) witnessed improvements in "unit leadership and visibility" inside and outside the institution. These observations can be explained by a reduction of stress and tensions at work. Along the same vein, some units observed a rise in their attraction and retention capacity (Bournes \& Ferguson-Paré, 2007).

Despite these positive findings, the status of nursing grand theories and conceptual models in relation to practice is often debated. Theory-based practice benefits from very little attention in "ordinary" clinical environments. This situation is often referred to as the "theorypractice gap", which designates the disparity between the vision embedded in grand theories and conceptual models and the "reality" of nurses in clinical settings. Nursing theories supporters explain it mostly by a lack of exposure among students, professionals in clinical settings, nursing educators, or managers (Alligood, 2014). On the other hand, nursing philosophers question the soundness of some grand theories and models, especially those falling into the "simultaneity" paradigm, such as the Human caring theory (Watson, 2012) and Humanbecoming theory (Parse, 1998, 2007). They are concerned that the underlying assumptions lead to moral confusion, particularly in reference to what constitutes "paternalism" in clinical situations (Hussey, 2004; Kikuchi, 1996; Risjord, 2014). However, these hypotheses have not been explored since all the reports have aimed to document the positive impacts of nursing theories in practice. More preoccupying, their benefits and their relevance tend to be less challenged nowadays due to their "patrimonial" status (Edwards, 2000; Rolfe, 2012; Thorne et al. 1998). Given these concerns, a study was conducted using a qualitative in-depth case study design (Yin, 2014) to describe the process and the effects of a theory-based nursing practice, as experienced by nurses as well as other members of the institution.

\section{The case: The Humanbecoming theory in a palliative care unit in Canada}

From 2008 to 2009, nurses and other professionals from a 15-bed palliative care unit in Canada were involved in an initial research project (2007-2010) dedicated to developing and 
evaluating practices aimed at enhancing patient autonomy of people at the end of life. This research team chose to implement the Humanbecoming theory (HBT) because of its great emphasis on person-centered care and its coherence with palliative care philosophy (Hutchings, 2001, 2002; Lee \& Pilkington, 1999; Stanley \& Meghani, 2001). Researchers used an action research design adapted from the Parse's pre-post implementation qualitative design. Over a 12month period, nurses and other members of the institution took part in weekly meetings and seminars modelled upon Parse's Teaching-learning model (Parse, 2004). Participants reported that they were more in "true presence", which meant for them to be authentic and to foster "humane relationships". More precisely, HBT led them to be more attentive and respectful of patients' choices and desires. They also tended to better valorize people's diversity, uniqueness, and dignity (Lavoie, Blondeau, \& Martineau, 2013).

The rationale behind the selection of this particular setting for this case study (2011-2014) was based on similarities of the implementation process and the findings obtained in other studies (Hammersley, 2012; Sandelowski, 1993, 2011). Indeed, this "theoretical" convergence is one way of ensuring the validity of case study results (Yin, 2014). As in the expression "to compare apples to apples", theoretical validity refers to the confidence that one will able to draw or infer theoretical generalizations from the case in comparison with others or previous ones. Given the complexity and the rareness of this object of interest, it would have been impossible to conduct the same study in other settings without compromising the depth of the study. Furthermore, the selection of this specific setting was significant considering that the implemented theory is one of the most challenged in regard to its ethical, philosophical, and practical underpinnings. This case study had two specific objectives:

- describe caregivers' perspectives regarding previous nursing practice within the institution, the implementation and integration of HBT, as well as personal, professional and organizational effects attributed to it;

- $\quad$ explain the challenges, including ethical challenges, associated with the learning and practice of HBT.

\section{Sample}

After approval by the hospital and university research ethics committees, data collection took place from mid-January to the end of August 2012. Recruitment strategies included informational letters, posters located in strategic rooms such as the cafeteria and the nursing office, and a few 10-minute long project presentations. During these presentations, participants were informed that the study aimed to gather different perspectives and that the researchers intended to remain as neutral as possible.

Participants were caregivers and workers of the institution who were willing to share their opinions about HBT and its use within the institution. While favouring the inclusion of nurses in our sample, other professionals, care volunteers, support employees, and managers were actively encouraged to participate (see Table 1). Having attended seminars or training sessions about the approach was not a requirement, as the external perspective was also sought. However, patients were not involved in the study given the longitudinal and specialized nature of the study. Written or orally informed consent was obtained from participants according to the different data collection strategies. 
Table 1 Repartition of participants, sociodemographic data, training and general attitude toward HBT

\begin{tabular}{|c|c|c|c|c|}
\hline $\begin{array}{l}\text { Participant category and } \\
\text { code }\end{array}$ & $\begin{array}{l}\text { Years of } \\
\text { experience in } \\
\text { palliative care }\end{array}$ & $\begin{array}{l}\text { Years of } \\
\text { experience in this } \\
\text { particular setting }\end{array}$ & $\begin{array}{l}\text { Gender (M=Male, } \\
\text { F=Female) }\end{array}$ & $\begin{array}{l}\text { Received training } \\
\text { on HBT ( } \mathrm{Y}=\text { Yes, } \\
\mathrm{N}=\mathrm{No} \text {, I=initial or } \\
\mathrm{C}=\text { continuing) }\end{array}$ \\
\hline Manager (Man1) & 8 & 3 & M & $\mathrm{Y}-\mathrm{C}$ \\
\hline Manager (Man2) & 11 & 11 & $\mathrm{~F}$ & $\mathrm{Y}-\mathrm{C}$ \\
\hline Nurse (Nurs2) & 5 & 5 & $\mathrm{~F}$ & Y-I \\
\hline Nurse (Nurs3) & 0,5 & 0,5 & $\mathrm{~F}$ & $\mathrm{Y}-\mathrm{C}$ \\
\hline Nurse (Nurs4) & 33 & 7 & $\mathrm{~F}$ & $\mathrm{Y}-\mathrm{I}$ \\
\hline Nurse (Nurs5) & 2 & 0,5 & M & $\mathrm{N}$ \\
\hline Nurse (Nurs8) & 6 & 5 & $\mathrm{~F}$ & $\mathrm{Y}-\mathrm{I}$ \\
\hline Nurse (Nurs9) & 2 & 1 & $\mathrm{~F}$ & $\mathrm{~N}$ \\
\hline Nurse (Nurs10) & 5 & 5 & $\mathrm{~F}$ & $\mathrm{Y}-\mathrm{I}$ \\
\hline Support employee (Sup1) & 3 & 3 & M & $\mathrm{Y}-\mathrm{C}$ \\
\hline Support employee (Sup3) & 24 & 24 & $\mathrm{~F}$ & $\mathrm{Y}-\mathrm{C}$ \\
\hline Volunteer (Vol1) & 1 & 1 & $M$ & $\mathrm{~N}$ \\
\hline Volunteer (Vol2) & 0,5 & 0,5 & $M$ & $\mathrm{~N}$ \\
\hline Volunteer (Vol3) & 10 & 10 & M & Y-I \\
\hline Volunteer (Vol4) & 8 & 8 & $\mathrm{~F}$ & $\mathrm{Y}-\mathrm{C}$ \\
\hline Nurse (Nurs1) & 4 & 3 & $\mathrm{~F}$ & $\mathrm{Y}-\mathrm{C}$ \\
\hline Nurse (Nurs6) & 11 & 10 & $\mathrm{~F}$ & $Y-1$ \\
\hline Manager (Man3) & 12 & 12 & $M$ & $\mathrm{Y}-\mathrm{I}$ \\
\hline Nurse (Nurs7) & 35 & 28 & $\mathrm{~F}$ & $Y-1$ \\
\hline Physician (Phy1) & 12 & 9 & $M$ & $\mathrm{~N}$ \\
\hline Physician (Phy2) & 12 & 12 & $\mathrm{~F}$ & $\mathrm{~N}$ \\
\hline $\begin{array}{l}\text { Psychosocial team } \\
\text { member (Psyc1) }\end{array}$ & 26 & 25 & $M$ & $\mathrm{Y}-\mathrm{C}$ \\
\hline $\begin{array}{l}\text { Psychosocial team } \\
\text { member (Psyc2) }\end{array}$ & 28 & 4 & $M$ & $\mathrm{Y}-\mathrm{C}$ \\
\hline $\begin{array}{l}\text { Psychosocial team } \\
\text { member (Psyc3) }\end{array}$ & 9 & 8 & $M$ & $\mathrm{Y}-\mathrm{C}$ \\
\hline Support employee (Sup2) & 5 & 5 & $M$ & $\mathrm{Y}-\mathrm{C}$ \\
\hline Total: 25 participants & Mean: 10,92 & Mean: 8,02 & $M=12 F=13$ & $Y=19, N=6$ \\
\hline
\end{tabular}

\section{Data Collection}

One or two semi-structured, individual interviews of 25 participants were conducted. Considering that the unit employs approximately 50 full-time employees, this number and the diversity of sample participants had the purpose of obtaining different positioning levels on the phenomenon of interest (Blumer, 1969). The majority of interviews lasted between 60 and 120 minutes, and the majority of them were held in an office dedicated to research activities, located in a quiet and discreet area of the building. Interviews were all conducted in French according to the same guidelines, including an open-ended question at the beginning, followed by complementary questions (see Figure 1). Interviews were audiotaped and transcribed verbatim by the researcher and an assistant. Verbatim concordance with the audio material was assured 
through the verification of samples by the principal investigator of the study. For the purpose of writing this paper, the translation of some participants extracts was made by a professional English reviewer.

Figure 1: Interview Guide

\section{Context:}

The organization in which you work began to implement in 2007 the Humanbecoming theory $(1998 ; 2007)$ into nursing practice and also into other sectors. Since that time, some people are trying to integrate it into their practice.

\section{General question:}

Could you describe your experience with this project?

\section{Elements of precision:}

1) Could you describe how things were before implementation?

a) Individual perspective

i) Personal (perceptions and experiences-introspection, relationship with the nursing profession, discipline, etc.)

ii) Professional (relationship with patients, quality of care, interprofessional collaboration, etc.)

iii) Organizational (work related and the organization, relationships with colleaguestypes)

b) Collective perspective

i) Collective practice (routines, functional model, institutional, medical, etc., specific clinical problems, etc.)

ii) Relationships and organizational climate (work satisfaction, organizational climate, etc.)

2) How did you feel about the implementation and integration of this approach to care?

a) Detail the training received, what you retained

b) Theoretical learning (related to the content of the approach, values and beliefs, etc.)

c) Practical learning (transition to practice)

d) Integration into practice

e) Explain the organizational climate (overall working atmosphere) before implementation and throughout the process

3) If applicable: What was your role and what have you done to implement this approach in your community?

a) Detail the training process

b) Describe the procedures (steps) associated with the implementation of the approach

4) How was it for you to learn and integrate this approach into your practice? 

a) Theoretical learning (related to the content of the approach, values and beliefs, etc.)
b) Practical learning (transition to practice)
c) Integration in practice

5) Could you describe what this approach has brought to you and how is it for you today?

a) Individual perspective

i) Personal: Personal Experience (feeling of transformation, personal growth, etc.);

ii) Relationship with the profession and the discipline (feelings of pride, more conscious of the nursing professional role/contribution, etc.).

iii) Professional: Relationship with patients (difficult and positive situations, respect for their choices, values, listening, refusal, quality of life, etc.); impacts on quality of care ( \pm falls, complaints, medication errors, pressure ulcers, etc.); Interprofessional collaboration (improved, various reactions, etc.)

b) Collective Practice

i) Conflicts and dilemmas, better image and added value of nursing, structure, etc.

ii) Relationships and organizational climate (magnitude and future of the project, nurse and patient consequences, continuing education, etc.).

Non-participant observation of clinical and interprofessional meetings was also carried out, including day and night shift reports and continuing education sessions ( $\mathrm{n}=20$ meetings). Five nurses were also observed during day and night shifts $(n=10)$. Medical charts of deceased patients $(n=20)$ were analyzed as well. These records shed light on clinically or ethically difficult situations that involved reference to or the enactment of HBT. They were selected based upon participants' suggestions. These two complementary data collection procedures aimed to identify the explicit and implicit place accorded to HBT and to patient preferences within the unit's practices. It also constituted a significant occasion to examine live patient/family-nurse interactions or reports of nursing and healthcare providers' actions in complex situations. Particular attention was paid to oral or written references and to remarks made about the theory by members of the institution through the use of its associated words, concepts, or paradoxes. All data gathered during observation and the chart reviewing process were added to a field journal, as were the theoretical reflections made during the interviews. This triangulation of collection techniques aimed to contrast and combine data and, therefore, to foster the internal validity of the study (Gagnon, 2010; Yin, 2014).

\section{Data Analysis}

Gathered data was organized and analyzed using the QDA Miner software (4.0.4). Technically, the coding process consisted of two cycles including several iterations. The first cycle of coding included a descriptive coding, which consisted of converting the essential thought of each idea expressed by participants into a very short synthesis (Saldana, 2013). This method led to the creation of 1475 codes. The inductive creation of these codes made it possible to stay mindful of what data "had to say" and avoid "taken for granted" inferences (Yin, 2011) 
After this stage, a first grouping of these codes into 220 emergent themes was carried out, and these themes were then classified into large pre-set categories mainly derived from the first objective, which contained a temporal component (previous practice, implementation, and integration in practice and effects).

The second cycle of coding consisted of a theoretical or schematic organization of first level descriptive themes. Technically, the thematic networks technique was manually used to organize themes and find relations between them (Attride-Stirling, 2001). The themes were also compared and their similarities and discrepancies were examined. This process led to the identification of different patterns and trends in some participants' perspectives, notably about the implementation phase of the project, understanding of HBT, and its effects within this particular institution (Tapp, 2014). These patterns and trends led to the elaboration of the major categories that will be presented in the next section. Clarification interviews were carried out among four key informers in order to test some explanations and further gather their point of views on the matter. This process aimed to foster the internal validity of the findings. The interviews were held in similar conditions as the initial interviews and were submitted to the analogous manipulations, which comprised a codification process to compare and refine themes and categories obtained from the previous analysis.

\section{Results}

Perspectives on HBT, its use, and its effects in the institution were diverse. It was possible to trace two divergent discourses about what existed before the project, the implementation and integration of HBT, and the personal, professional, and organizational effects attributed to it. This article focuses on the major categories associated with participants' utilization of HBT in their practice, according to the two different discourses.

\section{HBT as a growth opportunity}

The majority of nurses and care volunteers shared an overall positive account of the implementation, integration, and effects of HBT within the institution. Some of them had participated in the initial training (2008-2009) or the continuing education activities (2010-2011) on HBT. They spoke at length about how they were mainly focused on tasks and on treatments, instead of the patient's unique perspective on quality of life, before the implementation of HBT. "Ten years ago, what I was saying to you, was that we finished at 10:30 AM and said Yah! At 10:30 AM, we were finished giving baths!" (Vol3). These participants reported that satisfaction regulated according to "task" was omnipresent in their conceptualization of work. Therefore, HBT implementation and training allowed them to realize that this attitude acted as a barrier to their "presence" and their relationships with patients and relatives. As a result, the approach changed their representation of their professional or caring mandate, especially at the end of life, and made them "better caregivers and humans" (Nurs3). Indeed, they reported experiencing personal and intellectual growth through the learning of HBT. For example, Nurse 3 explained how it offers a thinking structure:

I'm more aware and the difference it makes, it's like, sometimes, it resonates in my head. HBT or the terms, the meaning or rhythm and then transcendence, it's as if it helps me to put words to it and then sometimes confirms what I have done is good, then I move on with a small... 'Aaah' (smile). 
However, for others, HBT did not reveal any philosophical or clinical novelty since the palliative care philosophy or other narrative approaches already cover these values and attitudes. They further shared that they didn't need to adhere to a specific approach in their clinical practice. Accordingly, for these participants, they clearly and unanimously stated that the implementation of HBT did not change anything for them personally, in their practice, or in the running of the institution. However, they did notice changes among some of their colleagues, such as improvement in their reflective abilities.

I'm under the impression that [colleagues] ask themselves questions from a different perspective when they have dilemmas, when they approach something, they have a basis for reflecting to resolve issues that may arise [...] or some approaches: "How do I support patient ways of being? Well, if I follow this philosophy, how can I go about it?" Given this or that situation, well "if there is a patient who wants something or doesn't want something, how do I offer it?" (Phyl).

\section{Perceived better relationships with patients and colleagues}

When questioned more precisely about what had concretely changed in their practices or in the institution, the vast majority of participants expressed that it remained essentially the same. Nurse 8, who had participated in HBT training since its beginnings, talked about its contribution to her clinical relationships:

My approach with patients has always been the same. I always say it [HBT] is the little extra that it brings to you... You know, we ask patients "Is there something I can do or anything else? Is there something that could...? Is there something you need and that we don't have?" Then often, we have a response... really, just right there."

Hence, changes in relation to patients and their families seemed to operate within nurses' perceptions of their relationships. The nurses and care volunteers reported that they created more meaningful and profound links with patients and their families. For example, training activities allowed them to deepen "the patient's meaning at that time" or "reasons for saying no to a treatment". They felt they were more disposed to act as sources of sharing, as Nurse 10 reported:

But for patients, I think it's an extraordinary philosophy [...]. You know, it allows you to enter the room, you know, to enter personal space, into the patient's universe. [...]. And then we can get, through this, to create a relationship. And often, when you get to see beneath what is going on and that people are willing to open up and talk about it, well the relationship is extraordinary. From that point on, there really is an atmosphere of trust.

These participants also held the opinion that overall, HBT may have helped to improve relationships with colleagues. A lot of them referred to a shared vision of the approach and a common understanding of the institution's goals. "It depersonalizes the system and brings forth a vision. And that vision, everyone made a small step towards a common vision. So it takes away [the judgments between colleagues] (Vol. 3)". This more global and perceptual perspective about HBT effects may provide some explanations for the finding that, in the collected charts and among the notes written by nurses who explicitly integrated HBT, there was no indication about specific topics of discussions or the documentation of patterns that could be related to Parse's practice methodology, except for one nurse who referred once to a patient's expression of some values and priorities about a treatment. Furthermore, during informal discussions and 
observations, people mostly mentioned the approach to highlight some tensions or difficulties in the institution. Some caregivers used it to claim the primacy of patients' preferences and caregivers' roles at the end of life.

\section{Also a source of tension in the institution}

Although some participants perceived an overall improvement in their clinical interactions and interprofessional collaborations, they also pointed out that their views regarding what meant to foster well-being or quality of life of patients at the end of life diverged from those of some colleagues who were not interested in what HBT was putting forth, even after a couple of years. Talking about what her colleagues would say about HBT, Nurse 3 said: "We already do it [here], regardless of whether it comes from the University or not, it may be more a source of questions, more about the relevance of implementing it in an environment where we are so good". In these participants' perspectives, some colleagues seemed, in fact, unable to conceive another way of being that would require that they drop their control over situations. In reference to giving absolute priority to patients' preferences, Nurse 1 explained:

"Most of the time the message gets through. But there are times, even with nurses, volunteers, well it does not, [there are] people who just cannot accept it. And it doesn't get through, but to accept that there is someone [...] it would be like being a bad nurse just to let it go. It's hard work".

Some participants did point out real differences regarding ways of acting with patients and their relatives. About having acted according to patients' wishes, some nurses discussed having been accused of giving up or "abandoning" the patient even though they had the firm conviction of having done the right thing. Nurse 2 said:

Well, [the patient] was asleep with the head like so... and the situation had saddened me because... [my colleague] thought I had abandoned [the patient], which was not entirely the case. On the contrary, I had respected what she wanted but [my colleague], she had like only... what appeared... She judged what "appeared" instead of the fact that...[the patient wanted to stay in this position].

In the opinion of these participants, "comments" about HBT highlighted prejudices or strictly personal opinions. This extract is particularly revealing:

There will always be people who go, like... I mean, as they move away starting to laugh, "Ah! My god, Humanbecoming!" Well, I said, although I didn't have the opportunity to say it to that person: "But this is because ... are you making fun of my beliefs? The fact that you don't believe in it, I mean no problem... if you believe in another philosophy, another... that's okay. But don't laugh... I don't laugh... So don't laugh either" (Nurs6).

These nurses were not only the victims of their colleagues' criticisms. HBT supporters were also pointing severe criticisms toward some members of their work team. They denounced what they recognized as "soft paternalism" towards some patients. In their opinion, rather than letting the patients choose what is right for them, some of their colleagues had a tendency to "impose" their decisions. They pointed out that these actions interfered with patients' dignity since they were disrespectful of their inherent liberty. Talking about a situation where a healthcare volunteer didn't ask a patient before opening the curtains, Nurse 2 exposed her rationale: "You will have a lot of problems because your intention was to do good. But at this point, wanting to do good, is an abuse! Because you didn't ask. You didn't look at what was going on". These HBT caregivers 
put forward the belief that people always choose what is best for them, based on what they think is good for them. Within a clinical perspective, Nurse 2 explained that she could offer some options to alleviate pain or discomfort, but that patients always have the last word:

The definition we have of "good" is not "his" definition of good. So if for him, he does not want the opioid and he wants to choke like crazy... You, you don't have the impression that you are doing good, but that is because, if you do not respect his wishes and you give him an opioid by using force in quotation marks, a manner of speaking, then you will not be respecting his wishes. You will be under the impression that you're doing your job, in a professional manner, because you know that's what he needs... But he, if he does not want your oxygen and then he does not want an opioid, what more can you do?

Thus, the respect of patients' decisional autonomy ${ }^{1}$ was central for these HBT supporters. They tended to give primacy to this ethical concept. Autonomy is considered to remain throughout life and even allows, according to the opinion of this participant, to explain or justify radical actions.

"If you're going to steal, it's because it appears for you as a means for justice. You're going to remove something from someone, you thought... We'll say it's not good. But you, your perception is not the same [...]. I can decide to commit suicide, but this is because it's my perception that this is the best thing I can do. I'm not saying that it is good, but it's me, my perception"(Vol3).

Similarly, during a nurse meeting, the moral properties of euthanasia and assisted dying were raised. The six nurses around the table rapidly came to the conclusion that, according to HBT, these practices would be morally acceptable on condition that they were people's requests. Unaware of the topic of discussion held in this meeting, another participant took the same example in order to expose the limits of this logic:

Is patient choice an absolute? Sometimes... Is the patient always well informed to make choices? What is the responsibility of the caregiver? So then, what appeared at this time was the issue of euthanasia, because it has been in the air a lot for a few years. So a patient who would say, "Well I ask to be euthanized". Well, if you take a certain way of conceiving Humanbecoming, well, that's what he wants. We dialogue with him, but if that's what he wants, then we do it. At this point, it contradicts, of course, our institution policy (Psyc1).

This "fixed and pre-determined" vision of HBT was, in fact, representative among some nurses and caregivers who used the approach as a "code" (Tapp, 2014). For example, this nurse explained: "When you read HBT, well you say to yourself... Well, that's because there is no possible compromise" (Nurs2). This perception of "prescribed" behaviours was prominent in some participants' accounts, such as this one:

It is as if we should meet all [patients' and relatives'] requests. Well, I know that there are things that are [Okay]... I know that it's okay that I have done or that I acted this way. But that comes all the time; I do not know what bothered me but especially situations that don't fit... There are situations where I say, "Ok that's okay, I made the

\footnotetext{
${ }^{1}$ The use of the term autonomy here refers to the decisional capacity and therefore the expression of wishes and desires by patients and relatives.
} 
good decision". If I had not been aware of HBT, it would not have been so difficult for me. But anyway, I don't know (Nurs1).

In fact, HBT "opponents" appeared more critical of this radical view of autonomy and its conformist imperatives than to the approach itself. Indeed, in their opinion, HBT in its written form did not solely promote the importance of respecting the wishes and the perspectives of patients as understood by some nurses and caregivers, but focused also on human existence as involving relationships with others and as continuously evolving in a community of people. According to their perspective, HBT values deeply "authentic presence" and "finding a balance" in relationships with others. Within this perspective, to practice HBT meant to consider patients' autonomy as socially anchored, which includes professionals' participation and contribution to people's perspectives and becoming. As Psyc3 shared:

We saw that there was, at the start perhaps, an initial understanding that it could be like [the choice at any cost]. Then after that, you know, no, it can't be like that in this [...] it doesn't hold water, we have to do things, the patient also has [...] as a person, he can tell us things but he also has responsibilities. Then, there are restrictions that we are all limited by [...], with which we have to deal.

The accounts of "what does it mean to practice with this approach" according to these professionals focused predominantly on "contextual clinical judgment", without ever mentioning the possibility of a pre-determined principle or vision of what constitutes a good or bad intervention at the end of life. According to this perspective, their feeling of competence remained stable over situations, even difficult ones. For them, it was more an "intrinsic state" that reflected itself in the decisions and interventions made in each particular situation in order to enhance patients' and relatives' well-being. However, participants brought forward the difficulties experienced by HBT nurses and other caregivers as they were trying to enact the good moral conduct corresponding to their representation of HBT. Describing a situation where a nurse felt uncomfortable as she was caring for a woman with acute respiratory distress and asked for help from her colleagues, this social worker explained:

During a formal group meeting, a [nurse] said that she had not been able to intervene with a patient. There was a lady in front of her who was suffering, [...] she was not able to do anything [to help her], she felt badly anyway [...] and someone else took over the situation. There was the connection with Parse, where in Parse, there is know-how but also interpersonal skills. And she, in the matter of the interpersonal skills... had not been great and the question was "What can we do to improve our interpersonal skills or our presence?”. So, I said, we are making the link with Parse's theory [...]. But people [...] recognized this devaluation of the nurse, and me, there I was thinking it's not true that Parse said that." (Psyc2).

Congruently, the nurse involved in this situation shared, in an individual interview, how her ideal according to HBT led to question her self-competency when she was unable to meet patients' and relatives' requests: "It's as if we had to respond to all requests, but it is not that. But we imagine that if we don't, we're not a good nurse" (Nurs1). Nurse 6, who took part in the original training but took a more distant stance toward HBT activities over the last few years, shared her global perspective about difficulties nurses had experienced with integrating this approach:

This created some situations where nurses had not considered themselves. Nurses also felt guilty at the same time, you know, not to get to meet the desires and needs of the 
person that you care for. At the same time, you are obliged to recognize that, in the time that... listen, this was an never-ending situation. At some point, they were in an emotional shock. So I know it was more difficult.

At the institutional level, problems associated with functional aspects of practices were also raised. For example, the coordination between sectors in complex situations prompted several reactions pertaining to the use of HBT. Some actions, aiming to integrate the theoretical "lessons" by respecting patients' wishes and choices led, in the words of a participant, "to functional imbalances whose echoes are still felt in the institution" (Psyc1). A vision also shared by Manager 3:

The support staff in there, they were hard hit because we put pressure on them to deliver. And we still have to keep watch. Let's say that I see among support staff and volunteers an openness to understand, at a certain level, some requests of nurses who are inspired by HBT. But we must not... we have to be careful that it does not become a pretext and that it puts even more pressure on us.

A lot of participants' accounts exposed the concept of "special requests" to please some patients. Instead of being little "extras" for patients, some caregivers considered them as "needs". This conceptual switch implied an obligation of fulfillment, imposed on them or on others, in order to remain truthful to HBT lessons. Therefore, in order to maintain the quality of services, and at the same time, to preserve their emotional and physical well-being and that of others, HBT supporters eventually reviewed their perspective about the approach and its practical applications within the unit. Some participants admitted having gone too far and found it necessary afterwards to set limits to their enactment of HBT principles. Nurse 1 stated: "[Some patients] require excessively, at some point, we become overwhelmed and like instead of setting our limits, we say, "No, no, it's Parse, it's HBT, and our work shift ends at crazy hours". For these participants, adjustments aimed to bring more flexibility and solidarity to their practices and to the institution's teamwork.

\section{Discussion}

In line with the previous studies on HBT or other theory-based practices, many nurses expressed satisfaction with learning and practicing according to HBT, which emanated from the feeling of having a better quality of working life. They said they had found meaning by integrating this approach into their practice, a finding which coincides with earlier writings (Bournes \& Ferguson-Paré, 2007; Gaudine, 2001; Jonas, 1999; Mitchell, 1999; Northrup \& Cody, 1998; Santopinto \& Smith, 1999). Some of them, evoking they had better relations with patients and experienced a positive impact on their quality of life, felt a greater sense of fulfillment. This assertion is comparable to the process of "positive feedback" reported about Watson's theory (St-Germain et al., 2008). Along with finding more meaning at work, nurses admitted having also found more purpose in their personal lives. As a result, HBT changed, as Parse already wrote, their perspective on their own existence, their relationships, and their environment (Parse, 1997). After having encountered a whole new dimension of knowledge and reality, they came to realize that their old worldview was incomplete and insufficient, acting as a catalyst for a "paradigm shift", as documented throughout the years by many authors in the theoretical domain (Alligood, 2014; Fawcett \& Desanto-Madeya, 2013; Parker \& Smith, 2010; Parse, 1999). For many participants in this group, this awareness led to greater reflexivity and rationality. This observation corroborates the results of previous studies linking the experience of 
personal and professional development with the integration of a nursing theory or model (Bournes \& Ferguson-Paré, 2007; Heggie, 1998). This current analysis may help to expand knowledge of this particular process, especially in regard to the relation between the use of HBT or another nursing theory as a reflexive tool and the feeling of contributing to the well-being of patients and having a better sense of meaning at work.

However, this study contributed to more clearly highlighting the difficulties and problems that may arise in the context of integrating HBT into practice. Indeed, the plurality of interpretations led to divergences with regard to the meaning of the approach and to its appropriate utilization in practice. In this sense, Gordon synthesized the different possibilities and concerns associated with the learning of formal models: "The reductionism of formal models can then go both ways: it simplifies and orders, but when taken too far or used in the wrong situations, it can obscure and exclude important dimensions of the situation" (Gordon, 2001, p. 234). She further adds: "there is also a danger that people think they know what they mean when in fact they don't, or that the meanings become so general as to be meaningless" (p. 241). Results of this study bear her out since issues related to radical or "non-nuanced" interpretations temporally led to personal and institutional problems.

Indeed, this vision induced effects such as feelings of guilt, frustration, and incompetence. Parse stated that these feelings were intimately linked to the use of the theory (Parse, 1999). However, rather than being attributable to the theory itself, participants linked them mainly to feelings of powerlessness generated by the inability to meet the "perceived" theory's ideals, which are mainly dependent on the decisional autonomy of patients. Indeed, the fusion of the beneficence and the decisional autonomy concepts led some nurses to think and feel, because of the fear of disrespecting them, that they did not have the legitimacy to propose some options or give some advice to patients and relatives. These difficulties reflect the same concerns previously expressed by Kikuchi (1996), Kikuchi and Simmons (1999), Hussey (2004), and Risjord (2014). Kikuchi was preoccupied with the blurring of moral frontiers and guilt feelings that the use of a theory such as HBT could foster given its relativistic ideals. In fact, Kikuchi criticized the fact that Parse rejects all forms of probable truths related to health and nursing, thus excluding the very notion of professional "expertise".

\section{Contributions and recommendations}

These results shed new light on the findings of past studies regarding the practical application of HBT. It counterbalances the positive effects that were previously systematically described and are still promoted in nursing theories discourse. Minimally, it introduces some empirical material that puts into perspective the "unquestionable" merits brought about by general statements such as those contained in grand theories and conceptual models. It also provides a foundation to address claims that systematically link these theories to good professional nursing practice. Without saying that they are, on the contrary, associated with unethical behaviours, the integration of a grand theory or a model should be considered as highly dependent on the nature of the institution and on the specific "symbolic logics" held by those involved, whether educators or learners.

Although these constructivist aspects of integration processes have been documented in the social sciences, including sociology, anthropology, and organizational behaviour science (Barnes, 2001; Diefenbach, 2007; Latour, 2005), the recognition of a distinctive and highly variable appropriation of the content of an approach was not explicitly stated in the literature 
regarding the implementation and integration of a grand nursing theory or a conceptual model, nor the diversity of its impacts. Indeed, in previous writings, regardless of the theory or model, the result of a "successful integration" into practice was taken for granted and therefore not examined in detail (Fawcett \& Desanto-Madeya, 2013; Heggie, 1998; Weiss, Hastings, Holly, \& Craig, 1994). For example, although Weiss et al. recognized that theories could, in fact, be unequally integrated and varied in effects, they linked these differences with actors' knowledge levels. The present study suggests that reinterpretation is inherent and omnipresent when learning a nursing grand theory or conceptual model, considering its ontological nature. Furthermore, participants that had a detailed understanding of the approach did not necessarily experience positive effects, which is antithetical to nursing theories supporters' arguments. These nuances echo Paley's philosophical reflections about the application of a nursing model into practice, which reveals to be a very subjective claim:

For very similar reasons, it is impossible to apply "caring" knowledge. Of course, it is entirely possible to claim that one is applying it; but that is hardly the same thing. For if there are no testable differences between one account and another, on what conceivable grounds can we decide whether this account, as opposed to that one, is being applied? (Paley, 2001, p. 196)

Therefore, when teaching or discussing the integration of grand theories and conceptual, models should not be represented as a direct translation of its content and, secondly, it should not be assumed that nurses will put this knowledge directly into practice and experience benefits from it. Therefore, using expressions such as "guide for practice" when referring to grand theories or conceptual models should be avoided because of the various possible interpretations. Terms such as "reflexive tool" could be preferable and suggest a more distant relation to knowledge (Charlot, 1997; Charlot, Bautier, \& Rochex, 2000; Longchamp, 2005). Instead of "adhering" to grand theories and conceptual models, nursing philosophers, scholars, and practitioners need to engage in a process of further critical analysis to determine if these offer "sound philosophical or scientific material" that help to improve understanding of phenomena relevant to nurses (Risjord, 2010; Thorne, Henderson, McPherson, \& Pesut, 2004). Moreover, it would be important to stress the plurality of sources of conceptualizations and levels of knowledge that are complementary to the health sciences and good professional practices, which enhance contextual clinical judgment (Benner, Sutphen, Leonard, Day, \& Shulman, 2010; Blondeau, 2002).

\section{Strengths and limits of the study}

Despite the interesting results obtained in this study, it is a well-known fact that the case study methodology regularly faces criticisms regarding its lack of "statistical generalizability" or external validity (Flyvberg, 2011; Yin, 2014). However, contemporary visions of science call for more nuances. In fact, Hammersley (2012) states that case studies operate in details about complex phenomena and that even if case researchers would like to study more cases to compare their findings, they would have to face time constraints and imperatives, as all researchers do. Also, some themes are uncommon and difficult to circumscribe. Their exploration and documentation remain nonetheless relevant, especially when researchers have good reasons to question the current or common representation of a phenomenon (Yin, 2014). This explains why case studies often situate themselves in a "falsification" enterprise, or at least in the indirect evaluation of existing knowledge (Flyvberg, 2011). Furthermore, because of the nature of the case study, it is not clear that the observations and findings presented in this report would replicate in other existing settings. Nevertheless, great precautions were taken throughout the 
study to ensure that the research process and the results were valid (Gagnon, 2010; Sandelowski, 2011; Yin, 2014).

However, the mainly "retrospective" scope of the research project represents a limit. Interview participants found it very difficult to point out long-term practical effects attributable to HBT. There may actually be very few tangible effects associated with the initial project. However, this could also be attributed to many other factors, such as "recall bias" among participants. Indeed, there was no clear line between what existed "before and after" HBT. As well, since the end of the project in 2009 , several events have since occurred that may have influenced current practices within the institution.

\section{Conclusion}

The purpose of this study was to closely examine the processes associated with the practice of integrating a nursing grand theory or conceptual model, and to examine its evolution. After eight months in the field conducting individual interviews, direct observations and chart analyses within a case study method (Yin, 2014), results showed that integrating a model can indeed produce positive effects, including a better quality of working life and a feeling of personal growth for nurses. However, it may incidentally engender other effects, such as guilt and sense of incompetence related to high and unrealistic moral ideals. This study emphasizes the importance of focusing on people's interpretation of the theory or the model, which may reveal to be radical. Nursing scholars and educators are thus invited to revise how they teach and what they say about nursing theories in their activities. 


\section{Declaration of Conflicts of Interests}

The authors declared no potential conflicts of interest with respect to research, authorship, and/or publication of this article. 


\section{References}

Alligood, M. R. (2014). Nursing Theory: utilization \& application (5th ed.). St-Louis, MO: Elsevier.

Attride-Stirling, J. (2001). Thematic networks: an analytic tool for qualitative research. Qualitative Research, 1(3), 385-405.

Barnes, B. (2001). Practice as collective action. In K. Schatzki, K. Knorr Cetina, \& E. Von Savigny (Eds.), The Practice Turn in Contemporary Theory (pp. 17-28). New York, NY: Routledge.

Benner, P., Sutphen, M., Leonard, V., Day, L., \& Shulman, L. S. (2010). Educating nurses: a call for radical transformation. San Francisco, CA: Jossey-Bass.

Blondeau, D. (2002). Nursing art as a practical art: the necessary relationship between nursing art and nursing ethics. Nursing Philosophy, 3(3), 252-259. doi:10.1046/j.1466769X.2002.00095.X

Blumer, H. (1969). Symbolic Interactionism: Perspective and Method. Englewood Cliffs, NJ: Prentice-Hall.

Bournes, D. A., \& Ferguson-Paré, M. (2007). Human becoming and 80/20: an innovative professional development model for nurses. Nursing Science Quarterly, 20(3), 237-253. doi:10.1177/0894318407303126

Charlot, B. (1997). Du rapport au savoir : éléments pour une théorie. Paris, France: Anthropos.

Charlot, B., Bautier, E., \& Rochex, J.-Y. (2000). École et savoir dans les banlieues-- et ailleurs (New ed.). Paris, France: Bordas.

Cody, W. K. (2013). Philosophical and theoretical perspectives for advanced nursing practice (5th ed.). Burlington, MA: Jones \& Bartlett Learning.

Diefenbach, T. (2007). The managerialistic ideology of organisational change management. Journal of Organizational Change Management, 20(1), 126-144. http://dx.doi.org/10.1108/09534810710715324

Edwards, S. D. (2000). Critical review of R R Parse's The Human Becoming School of Thought. A Perspective for Nurses and Other Health Professionals. Journal of Advanced Nursing, 31(1), 190-196. http://dx.doi.org/10.1046/j.1365-2648.2000.01246.x

Fawcett, J. (2005). Contemporary nursing knowledge: analysis and evaluation of nursing models and theories (2nd ed.). Philadelphia, PA: F.A. Davis Co.

Fawcett, J., \& Desanto-Madeya, S. (2013). Contemporary nursing knowledge: analysis and evaluation of nursing models and theories (3rd ed.). Philadelphia, PA: F.A. Davis.

Flanagan, J. (2009). Patient and nurse experiences of theory-based care. Nursing Science Quarterly, 22(2), 160-172. doi:10.1177/0894318409331937

Flyvberg, B. (2011). Case study. In N. K. Denzin \& Y. S. Lincoln (Eds.), The Sage Handbook of Qualitative Research (4th ed., pp. 301-316). Thousand Oaks, CA: Sage.

Gagnon, Y.-C. (2010). The case study as research method: a practical handbook. Québec City, QC: Presses de l'Université du Québec. 
Gaudine, A. P. (2001). Demonstrating Theory in Practice: Examples of the McGill Model of Nursing. Journal of Continuing Education in Nursing, 32(2), 77-85.

George, J. B. (2011). Nursing theories: the base for professional nursing practice (6th ed.). Upper Saddle River, NJ: Pearson Education.

Gordon, D. R. (2001). Research Application: Identifying the Use and Misuse of Formal Models in Nursing Practice. In P. E. Benner (Ed.), From novice to expert: excellence and power in clinical nursing practice (Commemorative ed., pp. 225-243). Upper Saddle River, NJ: Prentice Hall.

Hammersley, M. (2012). Troubling theory in case study research. Higher Education Research \& Development, 31(3), 393-405. http://dx.doi.org/10.1080/07294360.2011.631517

Heggie, J. R. (1998). The journey through perspective transformation: learning nursing theory. (PhD Thesis), University of San Diego, San Diego, CA.

Hussey, T. B. (2004). Intellectual seductions. Nursing Philosophy, 5(2), 104-111. http://dx.doi.org/10.1111/j.1466-769x.2004.00168.x

Hutchings, D. (2001). The experience of struggling in change for persons at end of life: Nursing research guided by the theory of human becoming. Journal of Palliative Care, 17(3), 201-202.

Hutchings, D. (2002). Parallels in practice: palliative nursing practice and Parse's theory of human becoming. The American Journal of Hospice \& Palliative Care, 19(6), 408. http://dx.doi.org/10.1177/104990910201900612

Jonas, C. M. (1999). Evaluation of the human becoming theory in practice in family practice. In R. R. Parse (Ed.), Illuminations: the human becoming theory in practice and research (pp. 347-365). Toronto, ON: Jones and Bartlett Publishers.

Kikuchi, J. F. (1996). Multicultural Ethics in Nursing Education: A Potential Threat to Responsible Practice. Journal of Professional Nursing, 12(3), 159-165. http://dx.doi.org/10.1016/s8755-7223(96)80040-8

Kikuchi, J. F., \& Simmons, H. (1999). Practical Nursing Judgment: A Moderate Realist Conception. Scholarly Inquiry for Nursing Practice: An International Journal, 13(1), 4355.

Latour, B. (2005). Reassembling the social: An introduction to actor-network-theory. Retrieved from Ariane database.

Lavoie, M., Blondeau, D., \& Martineau, I. (2013). The integration of a person-centered approach in palliative care. Palliative \& supportive care, 11(6), 453.

Lee, O., \& Pilkington, F. (1999). Practice with persons living their dying: A human becoming perspective. Nursing Science Quarterly, 12(4), 324-328. http://dx.doi.org/10.1177/08943189922107052

Legault, F., \& Ferguson-Paré, M. (1999). Advancing nursing practice: an evaluation study of Parse's theory of human becoming. Canadian Journal of Nursing Leadership, 12(1), 3035. http://dx.doi.org/10.12927/cjnl.1999.19070 
Longchamp, P. (2005, December). La confusion critique épistémologique des sciences infirmières. Carnets de bord, 10, 104-116.

MacLeod Dyess, S., Boykin, A., \& Bulfin, M. J. (2013). Hearing the Voice of Nurses in Caring Theory-Based Practice. Nursing Science Quarterly, 26(2), 167-173. http://dx.doi.org/10.1177/0894318413477138

Meleis, A. I. (2007). Theoretical nursing: development and progress (4th ed.). Philadelphia, PA: Lippincott Williams \& Wilkins.

Mitchell, G. J. (1999). Evaluation of the human becoming theory in practice in an acute care setting. In R. R. Parse (Ed.), Illuminations: the human becoming theory in practice and research (pp. 367-400). Toronto, ON: Jones and Bartlett Publishers.

Northrup, D. T., \& Cody, W. K. (1998). Evaluation of the human becoming theory in practice in an acute care psychiatric setting. Nursing Science Quarterly, 11(1), 23-30. http://dx.doi.org/10.1177/089431849801100107

Paley, J. (2001). An archaeology of caring knowledge. Journal of Advanced Nursing, 36(2), 188-198. http://dx.doi.org/10.1046/j.1365-2648.2001.01959.x

Parker, M. E. (2006). Nursing Theories and Nursing Practice. Philadelphia, PA: F.A. Davis.

Parker, M. E., \& Smith, M. C. (2010). Nursing Theories and Nursing Practice (3rd ed.). Philadelphia, PA: F.A. Davis.

Parse, R. R. (1997). Transforming research and practice with the human becoming theory. Nursing Science Quarterly, 10(4), 171-174. http://dx.doi.org/10.1177/089431849701000409

Parse, R. R. (1998). The Human Becoming School of Thought A perspective for Nurses and Other Health Professionals. Thousand Oaks, CA: Sage.

Parse, R. R. (1999). Nursing science: the transformation of practice. Journal of Advanced Nursing, 30(6), 1383-1387. doi:10.1046/j.1365-2648.1999.01234.X

Parse, R. R. (2004). Teaching-learning processes. A human becoming teaching-learning model. Nursing Science Quarterly, 17(1), 33-35. http://dx.doi.org/10.1177/0894318403260549

Parse, R. R. (2007). The humanbecoming school of thought in 2050. Nursing Science Quarterly, 20(4), 308-311. http://dx.doi.org/10.1177/0894318407307160

Risjord, M. (2014). Nursing and human freedom. Nursing Philosophy, 15(1), 35-45. doi:10.1111/nup.12026

Risjord, M. W. (2010). Nursing Knowledge: science, practice, and philosophy. Chichester, West Sussex, UK: Blackwell Pub.

Rolfe, G. (2012). Cardinal John Henry Newman and 'the ideal state and purpose of a university': nurse education, research and practice development for the twenty-first century. Nursing Inquiry, 19(2), 98-106. doi:10.1111/j.1440-1800.2011.00548.x

Saldana, J. (2013). The coding manual for qualitative researchers (2nd ed.). Los Angeles, CA: Sage. 
Sandelowski, M. (1993). Theory unmasked: The uses and guises of theory in qualitative research. Research in Nursing \& Health, 16(3), 213-218. doi:10.1002/nur.4770160308

Sandelowski, M. (2011). "Casing" the Research Case Study. Research in Nursing \& Health, 34(2), 153-159. doi:10.1002/nur.20421

Santopinto, M. D. A., \& Smith, M. C. (1999). Evaluation of the human becoming theory in practice with adults and children. In R. R. Parse (Ed.), Illuminations: the human becoming theory in practice and research (pp. 309-347). Toronto, ON: Jones and Bartlett Publishers.

St-Germain, D., Blais, R., \& Cara, C. (2008). The contribution of nurses' caring approach to patient safety in a rehabilitation setting: an innovative study [French]. Recherche en soins infirmiers, (95), 57-69.

Stanley, G. D., \& Meghani, S. H. (2001). Reflections on using Parse's theory of human becoming in a palliative care setting in Pakistan. The Canadian Nurse, 97(7), 23.

Tapp, D. (2014). Intégrer une conception infirmière dans la pratique : entre rapports au savoir, interprétations plurielles et mobilisation créative des acteurs. (Ph.D.), Université Laval, QC.

Thorne, S., Canam, C. J., Dahinten, S., Hall, W., Henderson, A., \& Kirkham, S. R. (1998). Nursing's metaparadigm concepts: disimpacting the debates. Journal of Advanced Nursing, 27, 1257-1268. http://dx.doi.org/10.1046/j.1365-2648.1998.00623.x

Thorne, S. E., Henderson, A. D., McPherson, G. I., \& Pesut, B. K. (2004). The problematic allure of the binary in nursing theoretical discourse. Nursing Philosophy, 5(3), 208-215. http://dx.doi.org/10.1111/j.1466-769x.2004.00189.x

Watson, J. (2012). Human Caring Science: a theory of nursing (2nd ed.). Sudbury, MA: Jones \& Bartlett Learning.

Weiss, M. E., Hastings, W. J., Holly, D. C., \& Craig, D. I. (1994). Using Roy's adaptation model in practice: nurses' perspectives. Nursing Science Quarterly, 7(2), 80-86. http://dx.doi.org/10.1177/089431849400700208

Yin, R. K. (2011). Qualitative Research from Start to Finish. New York, NY: Guilford Press.

Yin, R. K. (2014). Case Study Research: design and methods (5th ed.). Thousand Oaks, CA: Sage Publications. 